\title{
OS DEBATES SOBRE OS CURRÍCULOS NACIONAIS E A DEFESA DA EDUCAÇÃO DEMOCRÁTICA
}

\author{
Maria Luiza Süssekind (UNIRIO) \\ Universidade Federal do estado do Rio de Janeiro/UNIRio \\ Segunda Secretária Nacional da ANPEd-Associação Nacional de Pós-graduação e Pesquisa em \\ Educação. E-mail: luli551@ hotmail.com \\ ORCID: https://orcid.org/0000-0002-7296-615X \\ Maria Dilnéia Espíndola Fernandes (UFMS) \\ Universidade Federal de mato Grosso do Sul/UFMS \\ Vice-Presidente da Região Centro-Oeste da ANPEd - Associação Nacional de Pós-graduação e \\ Pesquisa em Educação. E-mail: mdilneia@uol.com.br \\ ORCID: http://orcid.org/0000-0001-5218-8541
}

\section{RESUMO}

Nesse artigo questionamos as políticas de currículos nacionais na perspectiva da disputa por um projeto de educação que, consequentemente, remonta à disputa por um projeto de sociedade. No centro de tal disputa se coloca um projeto excludente que mercantiliza a educação versus um projeto democrático que defende o direito à educação para todos enquanto valor universal.

Palavras-chave: política educacional; escola democrática; currículos nacionais;

\section{THE DISCUSSIONS ON NATIONAL CURRICULUMS AND THE DEFENSE OF DEMOCRATIC EDUCATION}

\begin{abstract}
In this article we question the policies of national curricula in the perspective of the dispute for an education project that, consequently, points out the dispute for a project of society. At the heart of such a dispute is an exclusionary project that commercialises education versus a democratic project that defends the right to education for all as a universal value.
\end{abstract}

Key words: educational policy; democratic school; national curricula;

\section{LOS DEBATES SOBRE LOS CURRÍCULOS NACIONALES Y LA DEFENSA DE LA EDUCACIÓN DEMOCRÁTICA}

\section{RESUMEN}

En este artículo cuestionamos las políticas de los currículos nacionales en la perspectiva de la disputa por un proyecto educativo que, en consecuencia, señala la disputa por un proyecto de la sociedad. En el corazón de tal disputa se encuentra un proyecto de exclusión que comercializa la educación frente a un proyecto democrático que defiende el derecho a la educación para todos como un valor universal.

Palabras clave: política educativa; escuela democratica currícula nacional;

\section{Introdução}

O artigo objetiva contribuir com a defesa e conceituação da escola pública democrática, laica e de qualidade social em momento singular da história do país quando forças conservadoras e privatistas intentam negar esse legado em diversos campos e com diversas estratégias, inclusive por meio de intervenções, influencias e interferências no desenho das políticas nacionais de currículos. Ajustando o foco no ensino médio, última etapa da educação básica brasileira, destinada aos jovens de 15 a 17 anos e adultos, 
apontamos, num esforço de mapeamento do debate, que o binômio Reforma do EMBNCC-EM (Base Nacional Curricular Comum-Ensino Médio; BRASIL, 2016; 2017) tende a reforçar e ampliar as desigualdades existentes além de comprometer a própria condição de democraticidade da escola.

Vimos argumentando, em artigos (SUSSEKIND, 2014a, 2014b, FERNANDES, 2018), e documentos, como pesquisadoras e também por meio da nossa associação (Associação Nacional de Pós-graduação e pesquisa em Educação - ANPEd), que na atual conjuntura, a proposição de uma Base (BNCC e BNCC-EM; BRASIL, 2017; 2017) nos termos em que está posta, na nossa avaliação, apresenta questões que ferem gravemente o direito à educação democrática porque nega a escola para todos.

Nesse sentido, retomamos o debate travado na audiência pública concedida pelo Conselho Nacional de Educação (CNE) à ANPEd e ABdC (Associação Brasileira de Currículos), realizada em 6 de agosto de 2018, onde apresentamos e discutimos dez razões (ANPED, ABDC, 2018) pelas quais a BNCC encaminhada pelo Ministério da Educação (MEC) não poderia ser aprovada com o objetivo de problematizar mais detidamente a dissonância entre esta e o que propõem, orientam e ordenam a legislação e as políticas para educação pactuadas nas CONAES $^{1}$ e na CONAPE-2018 ${ }^{2}$ sobre o que é uma escola democrática. A argumentação para tal se sustenta em farta produção da área sobre a temática, em posicionamentos públicos de entidades associativistas, sindicais, acadêmicas e culturais sobre a questão.

Diante disso, a primeira razão ${ }^{3}$ que se apresenta contrária a proposta de BNCC é que ela padece de legitimidade. Ela fere a Constituição Federal de 1988 e a Lei de Diretrizes e Bases da Educação Nacional (BRASIL, 1988; 1996) na medida que fere a organicidade da educação básica, definida como direito de todos. A segunda razão é a

\footnotetext{
${ }^{1}$ Conferências Nacionais de Educação.

${ }^{2}$ Conferência Nacional Popular de Educação.

3 "Os 10 motivos

1. Quanto à legitimidade da proposta.

2. Quanto aos entendimentos do direito à aprendizagem

3. A falácia da diversidade sob a forma de uniformização

4. Quanto à definição de educação integral

5. O problema da exclusão por outro ângulo: a educação de jovens e adultos (EJA) e outros excluídos da BNCC e da escola de tempo integral

6. A BNCC aponta para a redução de componentes curriculares exacerbando na simplificação do que são os "problemas" do EM, seus currículos, as escolas e as juventudes no Brasil.

7. O problema da noção de competência dissociada dos conhecimentos e de suas funções sociais.

8. Conteúdo não é base

9. O que não se diz sobre as experiências internacionais

10. Metodologia da construção da Base: pressa e indefinição.” (ANPED, ABDC, 2018).
} 
concepção de aprendizagem que a BNCC sustenta, tema que tem sido alvo de ampla discussão acadêmica nacional e internacional indicando seus equívocos epistemológicos e conceituais e já longamente debatido (ANPEd, 2015; MACEDO, 2015; PRICE, 2014; SUSSEKIND, 2014a; SUSSEKIND, 2014b; SUSSEKIND, PELLEGRINI 2016 ; SUSSEKIND, SALDANHA, PORTO, 2017; SUSSEKIND, PRESTES, 2017; OLIVEIRA SUSSEKIND, 2018; entre outros). Outras oito razões elencadas no documento chamam atenção para a proposta de diversidade concebida pela BNCC ser escamoteada sob a forma de uniformização, o que tem implicações e consequências graves para a proposição de escola de tempo integral, processos para inclusão de educação de jovens e adultos e demais setores da população que precisam ser incluídos no universo escolar. Tudo isto se agudiza com a proposição de redução de componentes curriculares, minimizando também os problemas reais e atuais do ensino médio, das escolas e das juventudes. Para garantir essa lógica, a proposta brasileira dialoga de modo ensurdecido com as experiências internacionais (SUSSEKIND, 2014a) e não considera o que grandes reformadores que já fizeram a autocrítica do modelo em seus países têm a dizer. Por tudo isso, ganha relevância na BNCC-EM uma noção de competências totalmente alheia às funções sociais do conhecimento que, por sua vez, é encaixotado, des-historicizado, desideologizado e despido de seu caráter interacional e simbólico. Numa direção diametralmente oposta ao que recomendou nossa associação em análise de documento anterior, a BNCC, definindo que "qualquer proposta curricular precisa considerar as adversidades e diversidades locais - de ordem étnica, cultural, social, política e econômica - e individuais, relativas a interesses e capacidades de aprendizagem, e aos direitos de respeito aos conhecimentos construídos antes e fora da escola, para além dos direitos de aprendizagem de conteúdos prescritos fora do universo social dos alunos e organizados sem levar em conta que estes são, e precisam ser, sujeitos de suas aprendizagens" (ANPEd, 2015).

\section{A educação democrática}

Em 1988, nos acalorados debates da constituinte afirmou-se a educação pública democrática como direito de todas as pessoas cidadãs, sendo dever do Estado e da família, conforme estabelecido no Art. 205 (CF, 1988). As disputas pela significação dessa expressão e entre estado, sociedade e família, pautariam nos 30 anos seguintes, as políticas para a educação evidenciando, no confronto com conservadores, privatistas e 
fundamentalistas movimentos de defesa das escolas públicas "como espaço de luta, resistência e proposição popular de um projeto contra hegemônico, de concepção democrática tendo o direito de todos/as à educação, como epicentro das políticas de Estado para a educação" (CONAPE, 2018).

E foi com esse objetivo que, desde a constituinte, durante a construção da LDB, e até os dias de hoje, associações como a ANPEd entre outras entidades da sociedade civil vêm se empenhando, há décadas, em discutir rumos que possam permitir essa conquista efetiva. Com esse espírito, foram organizados as CBEs (Conferências Brasileiras de Educação) nos anos 1980 e início de 1990, os CONEDs (Congressos Nacionais de Educação), a partir do final da década de 1990 do século passado e início dos anos 2000, e, posteriormente, a CONEB (Conferencia da Educação Básica), em 2008 e as CONAEs (Conferencias Nacionais de Educação) de 2010 e 2014. É relevante ressaltar, ainda, o importante papel do Fórum Nacional em Defesa da Escola Pública dos anos 1990 até 2004 e, posteriormente, o FNE (Fórum Nacional de Educação), que antes de ser desconfigurado com a destituição de grande parte das entidades que o compunham, em 2016 (Decreto Executivo de 26 de abril de 2017, da Portaria n 577 de 27 de abril de 2017), atuou de modo definitivo nessa construção.

Muito mais que debater leis ou participar em conferências, educadores, pesquisadores, associações e entidades da sociedade civil têm se empenhado em construir o sistema nacional de educação básica que apenas recentemente pode comemorar o acesso universal, mas ainda padece sob um ensino médio para cerca de um quarto de seu público real. Ao longo desses 30 anos de Constituição e 20 de LDB, ainda, protagonizaram importantes movimentos de resistência na defesa da educação pública democrática na forma de manifestações e greves de trabalhadores da educação, nas emblemáticas ocupações estudantis e em diferentes formas de debates, encontros e proposições.

Nas muitas negociações e ressignificações com o termo educação democrática perceberemos as lutas teóricas e políticas entre os diversos setores da sociedade, que por exemplo, alterariam, de modo significativo, sua definição, entre as CONAEs de 2010 e 2014. O Plano Nacional de Educação (PNE) inicialmente gravava que o montante dos investimentos do PIB deveriam ser na educação pública e acabou atendendo aos interesses de representantes de instituições de ensino confessionais e aos já declarados interesses de fundações e institutos privatistas garantiram que o texto final amarrasse o percentual ao investimento público em educação, tirando a educação pública do centro da política e dos 
recursos. Nos parece uma obviedade ressaltar que o caráter democrático da educação pública se vincula diretamente ao financiamento público para e no público. E que, portanto, qualquer investimento público em educação que não seja de fim público contradiz o próprio princípio democrático da educação pública.

Criticando o que chamou de "equívocos" da educação pública nos EUA, William Pinar, diante das políticas de unificação e controle curricular, questiona se a educação pública é para o público. E, se sim, afirma que deve então ser espaço de reconstrução de si mesmo e da sociedade e dos conteúdos (2008). Com ele, defendemos que a teoria do currículo rejeita a atual reforma do ensino "inspirada no mundo dos negócios", com sua ênfase em notas de provas padronizadas, análogos acadêmicos do produto final das empresas, isto é, "lucros" (Idem, p. 140-141).

Mas, a conceituação de democracia na educação ainda cederia mais espaço. Conforme sublinham Moura e Sales (2018), as concessões feitas aos setores cristãos e conservadores sequestram do documento parte da luta anteriormente incorporada. Assim, ferindo a ideia de democracia como pluralidade e diferença.

Enquanto o PNE 2001-2011, por inúmeras vezes, se refere a gênero, principalmente no tocante à questão da educação como meio de promoção da igualdade de gênero, o PNE aprovado no ano de 2014 só foi aprovado na Câmara dos Deputados após a retirada das duas menções ao termo. A primeira no inciso III do artigo 2o, cuja redação inicial estabelecia que "são diretrizes do PNE: superação das desigualdades educacionais, com ênfase na promoção da igualdade racial, regional, de gênero e de orientação sexual", foi substituída por "superação das desigualdades educacionais, com ênfase na promoção da cidadania e na erradicação de todas as formas de discriminação”. (Idem, p. 151, 152)

Como lutar contra uma discriminação que não pode ser nomeada? Frente às questões que desafiam a democracia como os preconceitos e desigualdades a batalha foi perdida pelos que defendiam a importância de escrever nos documentos que gênero, sexualidade, racismo e sexismo já habitam as conversas complicadas que são os currículos escolares com suas historicidades, glocalidades e alegorias. Habitam nos silêncios e, aqui, sem nome. Sabemos que as lutas foram longas e pesadas, e sabemos que as escolas são "arenas políticas e culturais" (MOREIRA, 1995, p. 13) nas quais os currículos, se elaborados/prescritos e entendidos como "conteúdos e métodos a serem aprendidos" (idem) serão inevitavelmente re-escritos, negociados e contestados em suas territorialidades se assumirmos as condições de interação e criação do social, além disso, 
admitir que professores são profissionais-intelectuais (MOREIRA, 1995, p. 12) e não reprodutores de conteúdos, sob o risco de se tornar, no mínimo, naïve. (SÜSSEKIND, 2014a, p 1516).

No âmbito desse debate, pairam questionamentos do campo da teoria curricular sobre controle e intencionalidade denunciando a possibilidade, ou impossibilidade conforme argumentamos (SUSSEKIND, 2014a), das políticas de unificação e o quanto oportunizam ou abduzem a democraticidade dos processos de ensinos-aprendizagens nos cotidianos escolares. Nesse sentido, a ANPEd manteve posição em defesa da pluralidade e da flexibilização como condições de democraticidade dos currículos definindo a cidadania pelo exercício livre da diferença, e afirmou que como quinto questionamento, a BNCC aponta para a redução de componentes curriculares exacerbando na simplificação do que são os "problemas" desse segmento, seus currículos, as escolas de ensino médio e as juventudes no Brasil. Ao afirmar que as noções fundantes da BNCC se apoiam na intencionalidade dos conteúdos, seja quanto ao desenvolvimento de competências ou da definição das chamadas aprendizagens essenciais4, mais uma vez reificam o currículo tornando-o um documento escriturístico que age como instrumento de controle e desvalorização do trabalho docente, que desconsidera o chão das escolas e inviabiliza a própria afirmação de que os currículos seriam diversos (p.11) e as juventudes autônomas e que "criem novas formas de existir". (ANPED, ABDC, 2018).

À miopia que guiou os debates teóricos complementou a pressa das consultas. A BNCC-EM consultou, mas não ouviu as escolas. Se as ocupações das escolas públicas e institutos federais de ensino médio havia sido uma resposta vultuosa, pulverizada, pululante e em alto e bom som à reforma do EM feita à canetada (SUSSEKIND, PELLEGRINI, 2016b), por Medida Provisória, a resposta à Base não seria menos amplificada. Protestos, documentos, audiências ocupadas por professores e estudantes organizados pedindo direito de voz.

\section{A flexibilização e os itinerários formativos}

Entre a audiência de agosto e a data que escrevemos este artigo, fomos surpreendidas pela apresentação à consulta pública, pelo CNE, de proposta de texto de

\footnotetext{
4 “os conteúdos curriculares estão a serviço do desenvolvimento de competências, a LDB orienta a definição das aprendizagens essenciais, e não apenas dos conteúdos mínimos a ser ensinados. Essas são duas noções fundantes da BNCC" p. 11
} 
Resolução que atualiza as Diretrizes Curriculares Nacionais para o ensino médio, tendo em vista as alterações introduzidas na LDB pela Lei no 13.415/2017. Alegando um biênio de preparação, o documento assimila a existência da BNCC e a ideia dos itinerários formativos e se apresenta como organização curricular com base em conceitos de unidades curriculares e arranjos curriculares. Desproporcional à imensa capacidade de ouvir a comunidade de especialistas no que tange à conceituação de currículo é a escuta às escolas, aos professores, às juventudes e, à operacionalização desta mesma noção. Pois, se, agora depois da BNCC-EM as novas Diretrizes do EM conceituarão currículo como a proposta de ação educativa constituída pela seleção de conhecimentos construídos pela sociedade, expressando-se por práticas escolares que se desdobram em torno de conhecimentos relevantes e pertinentes, permeadas pelas relações sociais, articulando vivências e saberes dos estudantes e contribuindo para o desenvolvimento de suas identidades e condições cognitivas e socioemocionais.

O currículo deve contemplar tratamento metodológico que evidencie a contextualização, a diversificação, e a transdisciplinaridade ou outras formas de interação e articulação entre diferentes campos de saberes específicos, contemplando vivências práticas e vinculando a educação escolar ao mundo do trabalho e à prática social e possibilitando o aproveitamento de estudos e o reconhecimento de saberes adquiridos nas experiências pessoais, sociais e do trabalho ${ }^{5}$. (BRASIL, 2018)

Não é possível garantir que sejam "Atendidos os direitos e objetivos de aprendizagem instituídos na Base Nacional Comum Curricular" condição explicita no paragrafo $1^{\circ}$ se houver "contextualização e diversificação". Uma premissa contraditória que cabe numa ideia de democracia de baixa intensidade pois garantir o atingimento de um objetivo conteudinal ou mesmo de aprendizagem não pode ser igual para todos se admitir que as escolas são locais de desenvolvimento de identidades e articulação de vivências e saberes. Quando defendemos que democracia é alteridade, e não mesmidade, nos afastamos da possibilidade de acreditar tanto na possibilidade de acesso a conhecimentos idênticos quanto na condição de verificação de aquisição dos mesmos, já que estamos assumindo que os conhecimentos contemplam as vivências, conforme diz o paragrafo $2^{\circ}$. Fluxos identitários e redes de conhecimentos dependem de acessos diferentes e comuns, de autonomia e autoria nas construções dos próprios trajetos e não de caminhos prescritos cujas diferenças se constroem pela aquisição ou não das competências de cada trajetória.

\footnotetext{
${ }^{5}$ Art. 7o e Parag. $2^{\circ}$, a saber.
} 
Pior do que unificar para igualar e com isso buscar uma homogeneização impossível e que, portanto, gera desigualdade, como a BNCC (MEC, 2017), a Base, a Reforma-EM e a nova diretriz coadunam-se numa "bomba de desigualdade" (ANPED, 2018) assumindo o modelo de corporação (PINAR, 2008, p. 142). Na resolução, existe a preocupação de estruturar a organização curricular que é coroada com a conceituação dos itinerários formativos como sendo conjunto de unidades curriculares ofertadas pelas instituições e redes de ensino que proporcionam que o estudante desenvolva todas ou algumas das competências e habilidades de uma ou mais áreas do conhecimento ou da formação técnica e profissional. (BRASIL, 2018)

Na contramão das construções históricas da sociedade brasileira desde o final da ditadura militar sobre o que seria uma educação democrática, a política curricular Reforma-BNCC-Diretriz oferece condições desiguais de partida e chegada. Sob a falácia da flexibilização, oferece simplificação e desigualdade. As escolas, como espaços de democracia, apresentam-se nesse contexto aos estudantes numa condição de oferta de uma cidadania que é reduzida ao mérito do resultado quando o ponto de partida também foi desigual. As vivências dos estudantes podem ser valorizadas ou silenciadas, mas contempladas, no sentido que assume fica quase negativo. Para a construção permanente da democracia nas escolas publicas já declaramos que

As desigualdades, diferenças e a diversidade social, cultural e econômica existentes no Brasil exigem, portanto, flexibilidade na norma curricular. Essa flexibilidade é incompatível com a definição de uma base nacional comum idêntica para todos, sob pena de entendimento do nacional como homogêneo e do comum como único, contrariamente aos princípios de respeito e valorização da pluralidade, fundamento da educação nas sociedades democráticas. (ANPED, 2015)

Nos Estados Unidos, precursores da unificação curricular, não só os resultados dos estudantes não melhoravam, como houve grande número de demissões de professores, causando longas greves, desgastes e, de certo modo, estimulando a charterização que produziu mais desigualdade do que havia antes. Para estudiosos do campo do currículo em acordo com Price "o maior problema com as Normas Comuns é a forma com que corporações, na cama com o governo, estão administrando a reforma educacional e, no processo, deixando de lado as vozes dos alunos, professores e pais" (2014, p. 15). Esse pesquisador denuncia ser um processo de privatização da educação pública baseado em práticas como "pagamento por mérito, e vigilância nas escolas" (Idem). Para Price, a 
unificação curricular não tem como objetivo senão "um currículo nacional, mas com corporações ao centro do governo" (PRICE, 2014, p. 16). Por isso, sob "tais condições, não é surpreendente que a promessa do programa de criar alunos que serão competitivos no mercado global de trabalho" (Idem, p. 15) soe oca, fazendo-o questionar para quem esse currículo seria comum." idem E, como lembra Price, o mercado capitalista exige diferentes competências e incompetências, suas diferentes (e hierárquicas) inteligências, gerentes e coaches (PINAR, 2008, p. 145).

Por isso temos denunciado a falácia da diversidade sob a forma de uniformização que reside na proposta da BNCC-EM que, mesmo propondo diferentes itinerários, os condiciona a uma suposta totalidade hierarquizante ${ }^{6}$. Assim, a tendência proposta para a formação humana é a modelização, o que provoca

homogeneização por meio da acentuação da perspectiva única, hegemônica, de abordagem dos diferentes temas e disciplinas, ignorando as especificidades dos educandos no que se refere a trajetórias de vida, afiliações sociais e culturais, étnicas, de gênero e outras, suas possibilidades e necessidades, buscando produzir identidades serializadas e eliminando as diferenças. Há uma fórmula estreita: um triângulo em cujos vértices estão a BNCC, a formação de professores e a avaliação em larga escala, estruturadas a partir de 4 objetivos de formação: competência, qualificação profissional, empregabilidade e avaliação de desempenho, atrelando essas instâncias e promovendo uma articulação aprisionante e padronizadora de aprendizagens e comportamentos docentes e discentes. (ANPED, ABDC, 2018)

Lembrando do $\S 1^{\circ}$ do Art. 26 da LDB (MEC, 1996) que determina que os currículos devem abranger "obrigatoriamente, o estudo da língua portuguesa e da matemática, o conhecimento do mundo físico e natural e da realidade social e política, especialmente do Brasil” interrogamos a BNCC, ainda sob mais dois aspectos: a flexibilização curricular como redução de quantidade de disciplinas e, a relação entre exigências e condições de oferta, ainda no caminho de questionamento da interpretação da lei que emana da BNCC-EM.

\footnotetext{
${ }^{6}$ É totalmente desconsiderado que, por maiores que sejam as possíveis críticas à organização disciplinar, as disciplinas têm história, vínculos com carreiras docentes e expectativas sociais, e não devem ser tratadas de forma naturalizada ou como repositórios de saberes. A proposta inicial de retirar do currículo disciplinas como Artes, Educação Física, Filosofia e Sociologia é apenas uma das evidências de que as disciplinas não são tratadas como instituições sociais que têm vínculos como variados projetos em curso nas escolas.
} (ANPEd, ABdC, 2018) 
A LDB afirma que a União, em colaboração com os Estados, DF, e Municípios define competências e diretrizes para a educação básica. $\mathrm{O}$ documento proposto como BNCC para o ensino médio afirma na sua introdução, que "as competências e diretrizes são comuns, os currículos são diversos" (Proposta de BNCC, p. 11). Em que pese o fato de que as especificidades locais podem e devem ser consideradas na elaboração de propostas curriculares, o que parece estar contemplado na proposta de BNCC apresentada, a interpretação da LDB que leva à redução da obrigatoriedade de disciplinas apenas à língua portuguesa e à matemática representa uma abdicação da União de suas responsabilidades, pondo em risco os direitos à formação integral dos estudantes desse nível de ensino.

Não faz sentido que uma BNCC eleja apenas português e matemática como disciplinas obrigatórias, quando a LDB indica um conjunto muito mais amplo de conteúdos essenciais para o pleno desenvolvimento humano, garantindo aos estados e municípios a gestão local, nacionalmente orientada. Ainda, e mais grave, se a BNCC se propõe a ser "um documento de caráter normativo que define o conjunto orgânico e progressivo de aprendizagens essenciais que todos os alunos devem desenvolver" (p. 7), a redução das disciplinas obrigatórias a português e matemática traz um esvaziamento do currículo do Ensino Médio inaceitável, que atingirá especialmente a população mais pobre do país atendida pelas escolas públicas, que convivem majoritariamente com os parcos investimentos de diferentes governos na educação, ocasionando falta de professores e de condições efetivas para a oferta de um ensino de qualidade. Reconhecer apenas a matemática e a língua portuguesa como disciplinas curriculares obrigatórias e transformar as demais disciplinas do atual currículo em componentes curriculares opcionais e temas transversais, traz certamente um enorme prejuízo do ponto de vista da formação humana e técnico-científica dos estudantes. Tudo o que não é português e matemática é delegado aos estados e às escolhas que fizerem, em virtude de condições e interesses locais. Resultado: padronização e eliminação da diferença ou do diferente em seus direitos à singularidade. $\mathrm{O}$ que isso significa? Jovens fora da escola. (ANPEd, ABdC, 2018)

Se "a valorização do local, das negociações e diversidade de sentidos, em suas manifestações autônomas em cada escola, em cada rede, é não apenas como entendemos ser necessário pensar qualquer construção de currículo" mas conquista da própria luta pela democracia e pelo reconhecimento do direito à diversidade, isso não pode ser feito a partir das condições locais. Conhecendo as desigualdades regionais e mesmo dentro de grandes centros urbanos no Brasil, é preciso ter cuidado com o que e como o ordenamento jurídico, 
legal e sobretudo a legislação e politicas para educação vão lidar com essas condições locais. Não pode ser negando acesso e oportunidades, nem por meio de decisões autocráticas. De acordo com o Art. 26 da LDB (MEC, 1996)

"Os currículos da educação infantil, do ensino fundamental e do ensino médio devem ter base nacional comum, a ser complementada, em cada sistema de ensino e em cada estabelecimento escolar, por uma parte diversificada, exigida pelas características regionais e locais da sociedade, da cultura, da economia e dos educandos. (Redação dada pela Lei no 12.796, de 2013, grifo nosso).

Portanto, no aspecto legal e executivo, é preciso enfrentar o duelo entre as exigências e as condições que foi deflagrado pelas políticas curriculares da ReformaBNCC-Diretriz-EM. Numa sociedade democrática, conforme entendemos na previsão da LDB, as exigências locais são prioridade em relação às suas condições. As comunidades escolares possuem direitos e, entre eles, está o de superar as condições (de desigualdade) locais. Nesse sentido, as condições, quando desfavoráveis, se tornam exigências e não o contrário. Logo, o caminho da reforma curricular não deve partir das condições, mas das exigências locais.

Cabe reforçar: não há base material que sustente as alterações feitas na LDB ou na BNCC para escolha de trajetórias pelos estudantes. Quem definirá as trajetórias são as condições de oferta dos sistemas, como ficou, de fato, estabelecido na Lei 13.415/17, e isto marcará profundamente o ensino médio como o campo da desigualdade oficial para as juventudes brasileiras. Não há garantias de que os sistemas educacionais consigam cumprir com a parte diversificada. A oferta de todos os itinerários formativos certamente não vai acontecer, os estudantes não terão a possibilidade da escolha como tem sido anunciado, ficarão restritos às possibilidades de oferta das escolas, conforme o ocorrido quando a lei 5692/71 tornou obrigatória a profissionalização simultânea à formação geral em todas as escolas e, poucos anos depois, teve que ser alterada pela absoluta impossibilidade do sistema educacional de dar conta da referida obrigatoriedade. (ANPEd, ABdC, 2018)

Ainda há outros desdobramentos a serem problematizados, como por exemplo, o retorno da profissionalização. Num cenário em que não se poderá garantir a oferta de todos os itinerários e nem da parte diversificada caso as exigências sucumbam às condições, no que tange ao das políticas para educação pública estamos falando de uma grave ameaça à sua condição de democraticidade. Estamos falando de negação de acesso. 
No caso, por exemplo, das pessoas jovens e adultas, das pessoas indígenas e quilombolas, como pensar itinerários apriorísticos? E se considerarmos as pessoas LGBTQ+ que retornam às escolas, segundo apontam as estatísticas, raramente, depois de diversas violências e expulsões ${ }^{7}$, nas turmas do regular noturno ou ainda mais comumente na EJA, e ainda são parte dos grupos cujo acesso ao ensino médio precisa ser muito ampliado, é justo definir/limitar itinerários e vocacionalidades?

A Base trazendo a profissionalização como itinerário formativo reedita o dualismo na Educação Brasileira, contra o qual gerações de educadores vêm se insurgindo desde a discussão e aprovação de nossa primeira LDB, a Lei 4024/61 e sua modificação pela lei 5692/71. Em documento da ANPEd (2016) questionamos a MP da reforma do EM alegando que nela as disciplinas são pensadas como melhor aproveitadas, quando reduzidas à organização por áreas porque isso levaria a uma melhor seleção por parte do aluno e uma melhor adequação à formação para o trabalho mas, isso sem considerar as inúmeras possibilidades de formações para os múltiplos trabalhos $\mathrm{e}$ as muitas possibilidades de mudanças nesse campo. Mais uma ameaça à possibilidade cotidiana de as escolas serem espaços de educação democrática, para, com e pela democracia. Uma reflexão importante e necessária quando se intensificam discursos que, em nome da "qualidade da educação", articulam políticas curriculares de homogeneização nas escolas e seus resultados nos desafiam a uma postura mais ofensiva de rompimento com "verdades" pré-estabelecidas, afinal, como afirma Macedo (2012): sem diferença não há educação.

Sob a Base, as juventudes e suas histórias e projetos de vida são homogeneizados e submetidos a um também impreciso "mundo produtivo". Contudo, ao que parece, a proposta desta reforma é que estudantes tenham a liberdade de escolher, dentre as disciplinas compreendidas como optativas, as que sejam de seu interesse para a composição de sua grade horária de estudos. Entretanto, é possível que em certas localidades de um estado sejam ofertadas várias dessas opções e em outras não haja escolhas, pois só é necessário que a rede ofereça poucas opções. Portanto, de fato, não há flexibilização quando são reduzidas as opções, tornando certas disciplinas optativas uma imposição para os estudantes. O que há é redução e homogeneização curricular.

Ou seja, ao se deslegitimar certas disciplinas, antes compreendidas como obrigatórias, nada garantirá a oferta de todas as disciplinas atualmente existentes para que

\footnotetext{
${ }^{7}$ Essas pessoas aparecem nas estatísticas educacionais sob a categoria de evadidos da escola. Entendemos que isso é uma injustiça pois as pessoas "viadas" são expulsas das escolas.
} 
os alunos possam fazer suas escolhas. Assim, ao invés de produzir qualidade e democracia, a reforma amplia algumas e legitima outras desigualdades dos sistemas. (idem)

Anteriormente, em documento enviado ao CNE a partir do documento (ANPED, 2018) alertamos que o modelo da reforma permite ampliar as desigualdades que pretende sanar e apagar o protagonismo das juventudes que defende.

Um documento que é "referência nacional comum e obrigatória" (p. 5) fixa habilidades, competências articulando-as às aprendizagens configurando-se, portanto, como um currículo unificado e, que, nesse sentido atua contra a diversidade e o protagonismo das juventudes que defende. E, mais grave, como "substituir o modelo único de currículo do Ensino Médio por um modelo diversificado e flexível” (p. 466) se o que se apresenta é um modelo reduzido ao mínimo? E se acompanhamos o ensino médio nos estados brasileiros nos últimos anos, podemos afirmar que as redes públicas estaduais tenderão a implementar o mínimo, o que afetará, conforme o Censo Escolar de 2016, $84,8 \%$ dos adolescentes e jovens brasileiros que estão matriculados nessa etapa.

Estudos e movimentos de jovens nos obrigam a dar ouvidos à complexidade das juventudes e à necessidade de que as escolas, se democráticas, sejam espaços de formação autônoma e autoral de juventudes plurais e com diversidade de experiências culturais. Contudo, nada parece mais distante da perspectiva de pluralidade e diversidade que uma escola que defina pragmaticamente que a inserção no mundo do trabalho exige apenas os conhecimentos das linguagens de português e matemática e toda a complexidade do conhecimento social, político, estético e artístico produzido até aqui seja parcelarizado em trajetórias desiguais à escolha dos sistemas de ensino. Em documento de 2016 junto a ABdC a ANPEd argumentavam que

Em linhas gerais a MP 746/2016 é um documento que pode ser caracterizado como um retrocesso para as políticas educacionais brasileiras para a formação de professores. É feita menção a um arremedo de flexibilização diante de proposições bastante diretivas que se abrigam sob os "itinerários de formação". Do modo como estes são propostos, destaca-se a dissociação entre proficiência e formação profissionalizante. Tal dissociação ressalta o caráter excludente de proposições que colocam em campos opostos: "áreas de conhecimentos ou de atuação profissional"8 (BRASIL, 2016).

Por fim, temos arguído a ideia de organização dos currículos por itinerários formativos entendendo sua impossibilidade de contribuir com a intensificação das

\footnotetext{
${ }^{8}$ Art 36, a saber.
} 
experiências democráticas no âmbito dos currículos, nos espaços das escolas públicas e na valorização das vivências de estudantes e docentes. Nesse sentido, a ênfase em cinco áreas distintas e sem a área de Ciências Sociais, tende a conferir ao currículo um caráter utilitarista, voltado unicamente ao atendimento de perspectivas futuras de inserção no mercado de trabalho, negligenciando, também, a função de "formação para a cidadania" prevista na LDB. Não é possível dimensionar o prejuízo que esse novo ordenamento pode causar, tanto no sentido de expulsar ainda mais das escolas as populações cujo acesso é instável, insatisfatório e quase invisibilizado quanto no sentido de ampliar as desigualdades já existentes dentro das redes e das regiões e entre redes e regiões.

O Novo Ensino Médio propagandeia que as crianças e os jovens do Brasil têm pressa. A educação precisa avançar. Esse avanço é apresentado na forma da "flexibilização do currículo", que provoca, homogeneização, simplificação e redução. Unificações curriculares não resolvem problemas de infraestrutura, não resolvem problemas de falta de professores, nem de falta de plano de carreira, de políticas de formação, etc. Como associação, temos repetido que as escolas são lugares de educação democrática, liberdade de pensar, ensinar e aprender.

A defesa da liberdade de pensamento é a defesa da pessoa humana. Nas ciências, nas religiões, no campo do direito, em cosmogonias ancestrais, a pessoa humana é dotada da capacidade de pensar livremente. As muitas formas de entender e explicar o mundo costuram esse emaranhado de diferentes olhares e sentires do mundo que nas universidades são pesquisados, debatidos, ensinados e avaliados. (ANPED ET ALII, 2018)

\section{Conclusão}

A educação democrática, cuja definição foi social e historicamente disputada e construída como sendo um "permanente processo de democratização em que a escola não é uma instituição pronta e acabada, pois a democracia só existe se e quando for democraticamente construída sob a perspectiva do respeito aos direitos humanos e o diálogo com os movimentos sociais. Para isso, a autonomia de cada escola é fundamento do processo de democratização, que requer, portanto, o esvaziamento de políticas educacionais padronizadoras em qualquer sentido ou esfera pedagógica. Assim, a educação pública democrática é necessariamente para todas as pessoas cidadãs, por isso é popular, gratuita, laica, inclusiva, de qualidade social e se contrapõe a todas as formas de preconceito sendo antiracista, antimachista, antisexista, antimisógina, antixenófoba, 
antilgbtifóbica, anti adultocêntrica, assim contribuindo para a superação de todas as formas de discriminação. (CONAPE, 2018)

Com efeito, defender um projeto de educação significa defender um projeto de sociedade. Neste sentido, a aprovação da Lei n. 14.005/2014 (BRASIL, 2014a) que instituiu o Plano Nacional de Educação 2014-2024 (PNE-2014-2024), demonstrou o quão isso é verdadeiro. Certamente, o processo de construção do PNE-2014-2024 que culminou com o Documento Final aprovado na Conferência Nacional de Educação (BRASIL, 2014b) e o texto jurídico-legal que resultou no PNE 2014-2024 aprovado pelo Congresso Nacional, sancionado pela Presidenta da República, foi expressão da luta com efetiva participação popular por um projeto de educação e consequentemente, de sociedade.

Da mesma forma que, diante de um tsunami neoliberal conservador (SUSSEKIND, 2018) no qual navegou o golpe legislativo-judiciário-midiático de 2016 (AMARAL, 2017), entrou em cena a contrarreforma social que, não por acaso, atacou e retirou direitos sociais duramente conquistados ao longo do tempo, entre estes os da educação quando a reforma para o ensino médio é uma das mais duras materialização do eixo da contrarreforma em curso.

Nessa perspectiva, quando falamos do ensino médio no Brasil, de qual escola estamos falando? De qual estudante estamos falando? De um estudante que chega nesse momento de vida que, dado o grau de desigualdade social historicamente construído no país, forçadamente, em razão do lugar social que ocupa, precisa decidir por um projeto de vida: se vai continuar seus estudos, projeto de médio e longo prazo, ou se irá se decidir por um projeto de vida a curto prazo que é se incorporar ao mercado de trabalho. Mercado de trabalho que, para essa idade, essa fase da vida, via de regra, é precário, temporário. Certamente a BNCC-EM não contribuirá para ampliar as oportunidades educacionais deste jovem já excluído por processos anteriores aos da escolarização, tornando-se uma "bomba de desigualdade" (ANPED, ABDC; 2018).

Por tudo isso, os questionamentos que fizemos à política curricular da Base ao longo desse artigo apontam para a avaliação de Penna de que estamos diante de um "projeto de escolarização completamente destituído de qualquer caráter educacional" (2016c, p. 46, Apud MOURA, SALES, 2018, p. 157) e, portanto, antidemocrático. O artigo aqui conclui na defesa nossa e de nossa associação, a ANPEd, de que cada pessoa, professor ou estudante, em cada sala de aula, em cada uma das mais de 200 mil escolas no 
Brasil seja sujeito de seus direitos de ensinar e aprender, com liberdade, valorizando a diferença na e com democracia.

\section{Referências}

AMARAL, Nelson Cardoso. O "novo" ensino médio e o PNE: haverá recursos para essa política?. Revista Retratos da Escola, Brasília, v. 11, n. 20, p. 91-108, jan./jun. 2017. Disponível em: <http://retratosdaescola.emnuvens.com.br/rde/article/view/759>. Acesso em: 16 out. 2018.

ANPED. BNCC do Ensino Medio: alguns pontos para o debate. Maio, 2018. Disponivel em: http://www.anped.org.br/news/nota-anped-proposta-de-bncc-do-ensino-medio-algunspontos-para-o-debate. Acesso em: 19.out.2018.

ANPED ET ALII. Por que defender a autonomia universitaria. 2018 Disponivel em: http://www.anped.org.br/news/por-que-defender-autonomia-das-universidades . Acesso em: 19.out.2018.

ANPED; ABDC. Ofício n. ${ }^{\circ}$ 01/2015/GR: Exposição de Motivos sobre a Base Nacional Comum Curricular. Rio de Janeiro, 9 de novembro de 2015. . Disponível em: $<$ http://ced.ufsc.br/files/2015/10/Exposi\%C3\%A7\%C3\%A3o-de-Motivos-a-BNCCANPED-e-ABdC.pdf>. Acesso em: 15.out. 2018.

ANPED; ABDC. Posicionamento sobre a Medida Provisória $\mathbf{N}^{\circ} \mathbf{7 4 6 / 2 0 1 6}$ sobre o Ensino Médio. 2016. Disponível em: <http://www.anped.org.br/sites/default/files/images/posicionamento_sobre_a_medida_pro visoria_do_em_abdc.pdf $>$. Acesso em: 15.out. 2018.

ANPED; ABDC. Exposição de Motivos: BNCC-EM. 2018. Disponível em: $<$ http://www.anped.org.br/sites/default/files/images/anped_abdc_contrabnccemago2018final.pdf >. Acesso em: 15.out.2018.

CONAE. FNE disponibiliza Documento-Final da Conae 2014. CONAE 2014, 28 Abril 2015. Disponível em: < http://conae2014.mec.gov.br/noticias/500-fne-apresentadocumento-final-da-conae-2014/500-fne-apresenta-documento-final-da-conae-2014 >. Acesso em: 13 out. 2018.

CONAPE. PROPOSTA DOCUMENTO BASE PLANO DE LUTAS. 2018. Disponível em: $\quad<\quad$ http://fnpe.com.br/docs/documentos/docsconferencia/proposta_documento_base_plano_de_lutas_final_apreciacao_pleno-22-052018.pdf > Acesso em: 15.out.2018.

FERNANDES, M. D. E. Gestão democrática da educação no Brasil: a emergência do direito à educação. Curitiba: Appris, 2018.

MACEDO, E.. Base nacional comum para currículos: direitos de aprendizagem e desenvolvimento para quem?. Educ. Soc., Campinas, v. 36, no. 133, p. 891-908, out.-dez, 2015. 
MACEDO, E.. The Notion of crisis and the legitimation of curriculum discourses in Brazil. In: REUNIÃO ANNUAL DA AMERICAN ASSOCIATION FOR THE ADVANCEMENT OF CURRICULUM STUDIES TRABALHO, 2012, University of British Columbia, Vancouver.

MOURA, F. P. ; SALLES, D. C. O Escola Sem Partido e o ódio aos professores que formam crianças (des) viadas. Revista Periódicus, 1(9), 136-160, 2018.

OLIVEIRA, I., SÜSSEKIND, M.L. Dimensões político-epistemológicas do equívoco conservador na educação: a base curricular brasileira no contexto dos currículos nacionais. (NO PRELO). Revista Portuguesa de Educação, 2018.

PINAR, W. F.. A equivocada educação do público nos Estados Unidos. In R. L. Garcia, \& A. F. B. Moreira (Orgs.), Currículo na contemporaneidade: Incertezas e desafios. São Paulo: Cortez, 139-148, 2008.

PRESTES, E.; SÜSSEKIND, M. L. ARMADILHAS E ESPELHOS: PENSANDO POLÍTICAS DE CURRÍCULO NUM CONTEXTO DE DEMOCRACIA EM RISCO. REVISTA COMMUNITAS, [S.1.], v. 1, n. 2, p. 491-513, nov. 2017. ISSN 2526-5970. Disponível em: <http://revistas.ufac.br/revista/index.php/COMMUNITAS/article/view/1512>. Acesso em: 16 out. 2018.

PRICE, T. A.. Comum para quem?. Revista e-Curriculum, 12(3), 1614-1633, 2014.

SILVA, T. T., \& MOREIRA, A. F. B. (org). Territórios contestados: O currículo e os novos mapas culturais. Petrópolis-RJ: Vozes, 1995.

SÜSSEKIND, M. L.. As (im)possibilidades de uma Base Comum Nacional. Revista ECurriculum, 12(3), 151 -1529, 2014a.

SÜSSEKIND, M. L. Quem é William F. Pinar?. Petrópolis, RJ: DP\&A, 2014b.

SÜSSEKIND, M. L. Entrevista: Maria Luiza Süssekind. Revista da ADCPII. ano v, n. 1, ago, 2018.

SÜSSEKIND, M. L.; PORTO, M.; REIS, M.. The (Im) Possibilities of the Common: An Opinion on the Erasing of Differences in Brazilian Curriculum Reform. Sociological International Journal 2(1): 00027, 2018. DOI: 10.15406/sij.2018.02.00027.

SÜSSEKIND, M. L.; PELLEGRINI, R. Não existe pecado do lado de baixo do equador: Políticas de currículo, direito à educação e as escritas nunca escritas. Cadernos de Pesquisa, v. 23, número especial, São Luís, p. 43-56, dez, 2016 a.

SÜSSEKIND, M. L.; PELLEGRINI, R. "A escrita nunca escrita" ou por que (re)afirmamos nossa contrariedade à Base Comum. In. FRANGELLA, R. C. P. Currículo, formação e avaliação: redes de pesquisas em negociação. Curitiba: CRV, 2016b. p.129150 .

\section{Legislação consultada}


BRASIL. CONSTITUIÇÃO DA REPÚBLICA FEDERATIVA DO BRASIL DE 1988. Brasília, DF: Senado Federal, 1988. Disponível em: <http://www.planalto.gov.br/ccivil_03/constituicao/constituicaocompilado.htm〉. Acesso em: 16 out. 2018.

BRASIL. Lei no 9394, de 1996. Estabelece as diretrizes e bases da educação nacional. Lei No 9.394, de 20 de Dezembro de 1996. Brasília: Diário Oficial da União, 20 dez. 1996. Disponível em: 〈http://www.planalto.gov.br/ccivil_03/leis/L9394.htm〉. Acesso em: 07 jul. 2016.

BRASIL. LEI N ${ }^{\circ}$ 12.796, DE 4 DE ABRIL DE 2013. Brasília: Diário Oficial da União, 04 abr. 2013. Disponível em: <http://www.planalto.gov.br/ccivil_03/_Ato20112014/2013/Lei/L12796.htm>. Acesso em: 16 out. 2018

BRASIL. LEI N ${ }^{\circ}$ 13.005, DE 25 DE JUNHO DE 2014. Brasília: Diário Oficial da União, 25 jun. 2014a. Disponivel em: <http://www.planalto.gov.br/ccivil_03/_ato20112014/2014/lei/113005.htm>. Acesso em: 15 out. 2018

BRASIL. Plano Nacional de Educação PNE 2014-2024, Brasília: Inep, 2015.

BRASIL. MEDIDA PROVISÓRIA No 746, DE 22 DE SETEMBRO DE 2016. Brasília, 22 set. 2016. Disponível em: <http://www.planalto.gov.br/CCIVIL_03/_Ato20152018/2016/Mpv/mpv746.htm>. Acesso em: 15 out. 2018.

BRASIL. Base Nacional Comum Curricular: Quarta versão. Brasília: MEC/SEB, 2017.

BRASIL. LEI No 13.415, DE 16 DE FEVEREIRO DE 2017. Brasília, 2017. Disponível em: < http://www.planalto.gov.br/ccivil_03/_ato2015-2018/2017/lei/L13415.htm>Acesso em: 15 out. 2018.

BRASIL. Base Nacional Comum Curricular - Ensino Médio. (Versão pública) Brasília: MEC/SEB. 2017.

BRASIL. Resolução de Novas Diretrizes Curriculares do Ensino Médio. (Versão para consulta pública). Brasília: MEC/SEB, 2018.

Recebido: 05/03/2019

Aceito: 30/03/2019 